\title{
Coordinated investing with feedback and learning ${ }^{\star}$
}

\author{
DAVID GOLDBAUM ${ }^{\dagger}$
}

\begin{abstract}
This paper introduces assets for which the intrinsic value is endogenous to the amount of funding attracted. A Rational Expectations Equilibrium is developed. Additionally, simulations of the model based on bounded rationality explore the different market behavior under fundamental and momentum based investing strategies. Both strategies produce herding characteristics. The herding under the fundamental strategy approximates the optimal investing of a rational central planner. The momentum strategy results in suboptimal economic development.
\end{abstract}

JEL Codes: C63; D83; E2

Keywords: Learning; Investment; Growth; Agent-based Computational Economics

\footnotetext{
* The author wishes to express thanks to members of the Santa Fe Institute Macro Seminar, particularly to J. Doyne Farmer for useful comments that helped to move the project forward. Thanks also to David A. Miller for meaningful interaction.

${ }^{\dagger}$ Rutgers University, Department of Economics, 360 Dr. MLK Jr. Blvd., Newark, NJ 07102; Phone

973 353-5164, Fax 973 353-5819; goldbaum@andromeda.rutgers.edu
} 


\section{Introduction}

A common theme in a number of recent World Bank working papers is the feedback between investment in a developing or evolving economy and financial market reforms enacted by the country. Investment brings about reform. Reform brings about further investment. Some examples are Meigas (2001), Dollar (2002), Claessens et al. (2003), and Grais and Kantur (2003). Development can only be successful if there is a constant flow of sufficient funds to bring about the next stage in reform. If the reform stalls then the value of the initial investment will likely plummet. A decentralized market based approach to investing may not develop the coordination required to bring about the optimal outcome. A developing country with a sound program of reform may experience the equivalent of a bank run if independent investors nervously fear that other investors have lost confidence.

Financial market risk is typically captured by an exogenous randomly determined terminal value or dividend stream; however, what these examples highlight is the endogeneity of intrinsic value. Therefore, the risk each investor faces includes risk associated with the uncertainty of the investment activities of the rest of the market. The objective of this paper is to explore the interaction between individuals and the market when the asset's intrinsic value is determined endogenously.

The investment process becomes a coordination game. The initial condition distinguishing, for example, Latvia from Lithuania at the time of the break up of the Soviet Union may be less important than the progression of investment and reform that occurs within each country. If one country becomes the "hot" investment area, 
then the influx of funds spurs greater reform, creating a self-fulfilling confirmation of the positive designation. Froot et al. (2001) find empirical evidence in support of a bidirectional feedback between the flow of funds and returns.

Similar issues can be found in technology models with spillovers. Moretto (2000) examines a model with network effects in which adopting a popular technology is less expensive than adopting technology alone. One extension of the model explores the possibility that early adoption offers a higher payoff than late adoption. There are thus competing motivations for those considering the timing of technology adoption: acting later offers a cost savings and lowers risk while acting earlier offers greater payoff. The key feature to make this analysis relevant to the current work is that the technology typically requires sustained investment over an extended period of time.

Herding tends to be associated with inefficient outcomes. As explored by Froot et al. (1992) and Hirshleifer et al. (1994), herding refers to investors selecting to gather and trade based on the same information set, even though other information is available and potentially more accurate in revealing the intrinsic value of an asset. The setting developed in this paper demonstrates that herding behavior by investors may be the best of the available options, serving as a coordination devise in a setting in which coordination is more important than project selection.

Another form of herding, momentum trading, refers to investors buying and selling in response to a respective upward or downward trend in the price of an asset. DeLong et al. (1990), Hong and Stein (1999), and Barberis and Shleifer (2003) include momentum traders in markets with fundamental traders. The momentum 
traders tend to create excessive momentum, so that the price overreacts to new market information.

Herding has been used in international finance to explain currency crisis in developing countries. In particular, Banerjee (1992), Bikchandani et al. (1992), Caplin and Leahy (1994), Calvo and Mendoza (1996), and Chari and Kohoe (2003), argue that herding is the natural result of asymmetric information. Less informed investors rely on market information to reveal private fundamental information. Arifovic and Masson (2004) develop a model in which traders with heterogeneous expectations of the return offered by a developing country learn through imitation of more successful strategies. The flow of investor sentiment cause cycles of success, optimism, devaluation, and pessimism, restarting the cycle.

The model presented in this paper is a general exploration of a feedback between the popularity of an investment project and the ability of the project to develop through to completion. The time to full development is determined by the rate of investment in the project. The project's intrinsic value is endogenous through the length of the development time.

\section{Analytical Development of the Model}

Consider an adaptation of Lucas (1978). Output, $D_{t}$, is produced by $m_{t}$ distinct "mature" production units. The output is perishable and may be used for consumption, $c_{t}$, or investment, $i_{t}$. In addition to the $m_{t}$ mature units, there exists a pool of $K$ immature units, referred to as "projects". The immature units are not currently capable of production, but with the investment of resources can be developed into mature production units. The rate of growth of a project depends on 
the rate of resource expenditure on its development, $i_{t}^{k}$. Projects developed to maturity are replaced by new immature projects.

\subsection{The central planner's optimization problem}

Assume a single decision maker for the economy maximizing an aggregate utility function. In continuous time,

$$
V\left(\mathbf{d}_{0}\right)=\max _{c_{t}, i_{t}^{k}} E \int_{0}^{\infty} e^{-\rho t} u\left(c_{t}\right) d t
$$

subject to

$$
\begin{gathered}
D_{t}=c_{t}+\sum_{k} i_{t}^{k}, \\
D_{t}=D_{0}+\sum_{j=1}^{k-1} D^{j} \text { for } t(k-1)<t<t(k), \\
\dot{d}_{t}^{j}=f\left(i_{t}^{j}\right), j=k, \ldots, k+K-1, \\
d_{t k}^{k}=d^{m} .
\end{gathered}
$$

The total output at time $t$ is that which is produced by the initial production units, $D_{0}$, plus for time $t, t(k-1)<t \leq t(k)$, the output of the $m_{t}=(k-1)$ matured projects. Once mature, project $k$ produces at a constant rate, $D^{k}$. Productivity upon maturity is unknown until the time of maturity with $D^{k}$ characterized by $E\left(D^{k}\right)=$ $d^{m}$ and standard deviation $\sigma_{d}$. If $\sigma_{d}=0$ then the maturity value is known and (1c) simplifies to $D_{t}=D_{0}+(k-1) d^{m}$.

Prior to maturity, project $k^{\prime}$ s level of development is measured by $d_{t}^{k}$, the time $t$ "shadow" output. The project grows based on the magnitude and productivity of the resources invested as captured by equation (1d). As reflected in (1e), the project 
reaches maturity when $d_{t}^{k}$ reaches size $d^{m}$. The $k^{\text {th }}$ project to mature does so at the endogenously determined time $t=t(k)$, or simply $t k$ for convenience.

The current state is defined by the current economic output, $D_{t}$, and the degree of development of the existing set of $K$ projects. Vector $\mathbf{d}_{t}=\left\{D_{t}, d_{t}^{k}, d_{t}^{k+1}, \ldots\right.$, $\left.d_{t}^{k+K-1}\right\}$ contains this information.

The utility function satisfies the standard assumption of separability and continuous differentiability with $u^{\prime}\left(c_{t}\right)>0$ and $u^{\prime \prime}\left(c_{t}\right)<0$. The productivity of investment function satisfies $f\left(i_{t}\right) \geq 0, f^{\prime}\left(i_{t}\right)>0$, and $f^{\prime \prime}\left(i_{t}\right) \leq 0$ with $f(0)=0$.

To solve the optimization problem, it is convenient to divide the problem into time intervals delineated by the time of completion of a project,

$$
V\left(\mathbf{d}_{0}\right)=\max _{c_{t}, i_{t}^{k}} E \int_{0}^{t 1} e^{-\rho t} u\left(c_{t}\right) d t+\int_{t 1}^{t 2} e^{-\rho t} u\left(c_{t}\right) d t+\int_{t 2}^{t 3} e^{-\rho t} u\left(c_{t}\right) d t+\ldots
$$

The value at time $t=t(k-1)$ can be conveniently expressed as

$$
V\left(\mathbf{d}_{t(k-1))}\right) \max _{c_{t}, i_{i}^{k}} E \int_{0}^{\tau k} e^{-\rho t} u\left(c_{t}\right) d t+e^{-\rho \tau k} V\left(\mathbf{d}_{t k}\right)
$$

with $\tau k=t k-t(k-1)$. Solve the optimal control problem implied by (3) treating $e^{-\rho(t k-t)} V\left(\mathbf{d}_{t k}\right)$ as the salvage value in order to find the conditions for the optimal investment path within the time frame $t(k-1) \leq t<t k$. The first order condition, the transversality condition, and the transition equation produce $u^{\prime}\left(c_{t}\right) / f^{\prime}\left(i_{t}^{k}\right)=E\left(\lambda_{t}^{k}\right)$ and $\lambda_{t}^{k}=e^{-\rho(t k-t)} \frac{\rho V\left(\mathbf{d}_{t k}\right)-u\left(c_{t k}^{-}\right)}{f\left(i_{t k}^{-}\right)}$, which imply an optimal investment path such that $i_{t}^{k}$ satisfies the equation ${ }^{1}$

\footnotetext{
${ }^{1}$ Investment in project $k$ during this interval $t(k-1)<t \leq t(k)$ changes the $t(k)$ without changing $V\left(\mathbf{d}_{t k}\right)$. Investing in project $j \neq k$ does not change $t(k)$, but does change the state $\mathbf{d}_{t k}$ at the start of the next
} 


$$
\frac{u^{\prime}\left(c_{t}\right)}{f^{\prime}\left(i_{t}^{j}\right)}=e^{-\rho(t k-t)} \frac{\rho E\left(V\left(\mathbf{d}_{t k}\right)\right)-u\left(c_{t k}^{-}\right)}{f\left(i_{t k}^{-}\right)} \text {for each } j=k \ldots k+K
$$

The present value co-state $\lambda_{t}^{k}$ is the multiplier function on (1d). The consumption rate $c_{t k}^{-}$represents optimal consumption as $t \rightarrow t k$ from below, $c_{t k}^{-}=$ $D_{0}+\sum_{j=1}^{k-1} D^{j}-\sum_{j=k}^{k+K-1} i_{t}^{* j}$. It will be useful to define the optimal consumption rate $c_{t k}^{+}$as consumption at a time arbitrarily close to $t k$ after maturity, $c_{t k}^{+}=$ $D_{0}+\sum_{j=1}^{k} D^{j}-\sum_{j=k+1}^{k+K} i_{t}^{* j} . \quad$ The term $V\left(\mathbf{d}_{t k}\right)$ is the current value of the agent's consumption stream, evaluated just after the completion of project $t k$.

Equation (4) is not yet a reduced form solution for the optimal investment path as $V\left(\mathbf{d}_{t k}\right)$ remains endogenous to the consumption decision. Further discussion of the solution process is contained in the appendix. ${ }^{2}$

The co-state $\lambda_{t}^{k}$ reflects the tradeoff between time $t$ consumption utility and the expected future benefit of additional investment in project $k$. The value of $\lambda_{t}^{k}$ is anchored by the terminal condition that sets $e^{-\rho t k} u\left(c_{t k}^{-}\right)+\lambda_{t k} f\left(i_{t k}^{-}\right)-\rho e^{-\rho t k} V\left(\mathbf{d}_{t k}\right)=0$. A small change to the optimal path changes the terminal date. By the terminal condition, if $i_{t}$ is increased, the loss in contemporaneous consumption utility must be negated by the earlier arrival of the salvage value. Equation (4) reflects the trade-off

interval. The value of the state variable at the start of the next interval is simply the discounted value of completing the next project, thus making $V\left(\mathbf{d}_{t k}\right)$ a pass through for the value of completing project $j$ at $t(j)$.

${ }^{2}$ appendices are available on the JEBO website 
between utility at time $t$ and the benefits to completing the project at time $t k^{3}$

Assumption A. Assume $u\left(c_{t}\right)$ and $f\left(i_{t}\right)$ such that along the optimal consumption path, both $i$ and c are weakly increasing as the economy's resources increase.

Assumption A is necessary to prevent the economy from driving consumption to zero, either through over investment or over consumption of the economy's output. In a related setting, Dixit et al. (1975) find the conditions that produce sustainable rates of growth in consumption and saving as the continuous saving produces discrete jumps in income. Assumption A is also sufficient to create an environment in which sequential development of projects is superior to simultaneous development.

Proposition 1. The optimal investment strategy concentrates investment in a single project rather than distributing funds across multiple projects.

Proof: See appendix available on the JEBO website.

The proof establishes that the marginal benefit of investing in a project increases with the rate of investment and thus resources are better used by concentrating on a single project. The choice between sequential development and simultaneous development is a choice about when the project will be realize, not whether it will be realized. Sequential development brings about production of one project without delaying the maturity date of the others. Of course, given sequential development, it is better to develop the most productive projects first, but in choosing between sequential and simultaneous, it is better to have developed a low productivity project at $t k$ followed by a higher productivity project at $t(k+1)$ than it is to have both projects mature simultaneously at $t(k+1)$.

\footnotetext{
${ }^{3}$ A more intuitive expression results if $c_{t}$ is constant: $\forall t>t k, c_{t}=c_{t k}^{+}$. In this case, $\rho V\left(\mathbf{d}_{t k}\right)$ simplifies to $u\left(c_{t k}^{+}\right)$allowing $\lambda_{t}^{k}$ to represent the PDV of instantaneous increase in utility produced by bringing the time of maturity a moment closer.
} 
A number of benefits arise if investment decisions are directed by a single decisions maker. Primarily, the investor need not be concerned with the uncertainty induced by the unknown behavior of other investors. The joint venture between the World Bank and the Government of Sweden discussed by Meigas may benefit from such an arrangement.

\subsection{Independent investor}

Now consider the same set of investment opportunities but in a market in which $N$ independent investors, indexed $n=1, \ldots, N$, invest in order to maximize individual utility. The individual investor solves

$$
V\left(\mathbf{d}_{0}^{n}\right)=\max _{c_{t}, i_{t}^{k}} E \int_{0}^{t 1} e^{-\rho t} u\left(c_{t}^{n}\right) d t+\int_{t 1}^{t 2} e^{-\rho t} u\left(c_{t}^{n}\right) d t+\int_{t 2}^{t 3} e^{-\rho t} u\left(c_{t}^{n}\right) d t+\ldots
$$

subject to

$$
\begin{gathered}
D_{t}^{n}=c_{t}^{n}+\sum_{j=k}^{K} i_{t}^{k, n}=c_{t}^{n}+\sum_{j=k}^{K} P_{t}^{k} d S_{t}^{k, n}, \\
D_{t}^{n}=\Phi_{0}^{n} D_{0}+\sum_{j=1}^{k-1} \Phi^{j, n} D^{j} \text { for } t(k-1)<t<t(k), \\
\dot{d}_{t}^{k}=f\left(\sum_{j=1}^{N} i_{t}^{k, j}\right) j=k, \ldots, k+K-1, \\
d_{t k}^{k}=d^{m}, \\
\dot{\phi}_{t}^{k, n}=\frac{d S_{t}^{k, n}}{S_{t}^{k}}=\frac{i_{t}^{k, n}}{S_{t}^{k} P_{t}^{k}} .
\end{gathered}
$$

The new term $\Phi_{t}^{n}$ represents investor $n$ 's percent ownership of the completed project

$k$. Prior to maturity, $\phi_{t}^{k, n}$ tracks the investor's percent ownership as it evolves during the project's development. To invest in a project at time $t$, the investor buys shares of 
stock in the project at the rate $d S_{t}^{k, n}$ at price $P_{t}^{k}$. The total number of shares sold to date is $S_{t}^{k}=\sum_{n} S_{t}^{k, n}$.

The FOC associated with investment in project $k$ is

$$
u^{\prime}\left(c_{t}\right)=E\left(\lambda_{t k}^{a} f^{\prime}\left(i_{t}^{k}\right)+\lambda_{t k}^{b} \frac{\phi_{t}^{k, n}}{S_{t}^{k} P_{t}^{k}}\right) .
$$

Here, $\lambda_{t k}^{a}$ and $\lambda_{t k}^{b}$ are the multipliers on (5d) and (5f) respectively. The impact investment has on the timing of the project's maturity is captured by $\lambda_{t k}^{a}$ in an expression similar to the central planner's FOC,

$$
\lambda_{t k}^{a}=e^{-\rho(t k-t)} \frac{\rho V\left(\mathbf{d}_{t k}^{n}\right)-u\left(c_{t k}^{n-}\right)}{f\left(i_{t k}^{k-}\right)} .
$$

The second term, based on $\lambda_{t k}^{b}=e^{-\rho(t k-t)} \frac{\partial V\left(\mathbf{d}_{t k}^{n}\right)}{\partial \phi_{n}^{k}}$, captures the impact investment has on the investor's percent ownership of the project and how that affects the stream of utility upon the project's completion. The $\frac{\phi_{t}^{k, n}}{S_{t}^{k} P_{t}^{k}}$ term in (6) accounts for the cost of acquiring ownership. Taken together, the RHS of (6) captures the sum discounted value of the impact today's investment decision has on the investor's own future utility.

An individual's investing brings about externalities for the other investors. As a positive externality, investment in a project brings it closer to completion, benefiting all shareholders. A negative externality arises as agent $n$ 's increased ownership in a project dilutes the ownership of the other investors. The completion time of $t k$ in $\lambda^{a}$ and $\lambda^{b}$, and the individual investor's percent ownership, $\phi_{t}^{k, n}$, in the 
second term of (6) become dependent on the behavior of others. As a result, the time to completion of each project and the share ownership are subject to the expectations operator in (6).

In (4), only $V\left(\mathbf{d}_{t k}\right)$ is unknown to the central planner, reflecting the uncertainty in the terminal value of the project. Unlike the central planner, the individual investor can benefit from diversification. There is an opportunity cost to concentrating investment in a slow developing project. Distributing funds increases the chance of investing with the herd of other investors when the investment objective of the herd is unknown to the individual.

Another counter-productive incentive present in the individual's problem but not the central planner's is that $\lambda^{b}$ encourages the investor to put funds into those projects in which ownership can be acquired cheaply. The pricing of the investment project has not yet been discussed, but if shares in less developed projects are priced lower than those of more mature projects then the incentive underlying $\lambda^{b}$ leads to investing in less developed projects, all else equal. Thus, both the incentive to invest in soon-to-be-completed projects and the incentive to buy into projects cheaply appear in the RHS of (6) and can be in conflict.

\subsubsection{A Rational Expectations Equilibrium}

A REE can be created by imposing sufficiently favorable structure on the environment. Simplify the investment problem involve only the distribution of funds between projects; $i_{t}^{n}$ is a fixed proportion of income. Allow that $i_{t}^{k, n}=\omega_{t}^{k, n} i_{t}^{n}$, $\omega_{t}^{n} \mathbf{1}_{K}=1 . \quad$ By the nature of the investment no project can be shorted; $\omega_{t}^{k, n} \geq 0 \forall t, k, n$ 
Consider a homogeneous population of investors who differ only in the private signal on the value of each undeveloped project. Investor $n$ receives signal

$$
Y^{n, k}=D^{k} E^{k, n}
$$

or, in logarithms

$$
y^{k, n}=\ln \left(D^{k}\right)+e^{k, n} \text { with } e^{k, n} \sim N\left(0, \sigma_{e}^{2}\right) .
$$

Let $\ln \left(D^{k}\right)=\mu+\varepsilon^{k}$ with $\varepsilon^{k} \sim \operatorname{IIDN}\left(0, \sigma_{\varepsilon}^{2}\right)$. For $D^{k}$ distributed log normal, $d^{m}=E\left(D^{k}\right)=\exp \left(\mu+\sigma_{\varepsilon}^{2} / 2\right)$

In a $K=2$ setting, consider projects $A$ and $B$. Let

$$
\eta=\ln \left(D^{A}\right)-\ln \left(D^{B}\right)=\varepsilon^{A}-\varepsilon^{B}
$$

and

$$
s_{t}^{n}=y_{t}^{A, n}-y_{t}^{B, n}=\left(\varepsilon^{A}-\varepsilon^{B}\right)+\left(e_{t}^{A, n}-e_{t}^{B, n}\right)=\eta+m_{t}^{n}
$$

where $m_{t}^{n}=e_{t}^{A, n}-e_{t}^{B, n}$. The investor can estimate

$$
\begin{gathered}
E\left(\eta \mid s_{t}^{n}\right)=b s_{t}^{n} \\
\operatorname{var}\left(\eta \mid s_{t}^{n}\right)=b \sigma_{m}^{2} .
\end{gathered}
$$

To simplify notation further, allow that $\omega_{t}^{n}=\omega_{t}^{A, n}$ and thus $\left(1-\omega_{t}^{n}\right)=\omega_{t}^{B, n}$. Consider an individual function $h^{n}$ that maps investor $n$ 's private information into an investment strategy, $\omega_{t}^{n}=h^{n}\left(s_{t}^{n}\right)$.

Condition $\Delta:$ The function $h^{n}$ is monotonically increasing, $h^{n} \in[0,1]$, with $h^{n}(0)=$ $1 / 2$ and symmetric about $h^{n}(0)$.

Consider the special case of $K=2, N=2$. The setting is now one of a cooperative game. Knowledge of both one's own $h^{n}$ and the opponent's $h^{-n}$ ensures 
that observed $i_{t}^{k}$ is fully revealing of the opponent's private signal. Once both investors know both signals, they can reevaluate $\eta$ by computing $E\left(\eta \mid s_{t}^{1}, s_{t}^{2}\right)$. With this shared estimate, the two investors can coordinate on the project believed to have the greater maturity value. Assume common knowledge so that each investor's $h^{n}$ function is known to both investors. The resulting coordination represents a dominant Nash Equilibrium.

As the primary project approaches maturity, there may be incentive such that both investors deviate from this cooperative investment path to invest in the low cost immature project.

Proposition 2: A fully revealing equilibrium does not exist for $N>2$ or $K>2$.

Proof: A fully revealing equilibrium requires a unique mapping from the unobserved state to observed market behavior. Consider $Y_{t}=\left\{y_{t}^{n, k}\right\}$, the set of all time $t$ signals that combine to produce investment $i_{t}=\left\{i_{t}^{k}\right\}_{k}$ according to each individual investor's application of the shared $h$. Expectations are linear in the signals, but according to Condition $\Delta h$ is non-linear. The different elements of $Y_{t}$ produce different $\left\{E\left(D^{k}\right)\right\}_{k} \cdot$ QED

As a counter example, consider $N=3$ and $K=2$. Assume common knowledge and a shared function $h$. A realization of $s_{t}^{2}=s_{t}^{1}$ and $s_{t}^{3}=-2 s_{t}^{1}$ means that $E\left(\eta \mid s_{t}^{1}, s_{t}^{2}, s_{t}^{3}\right)=0$. For the market to indicate this equivalence with an initial $i_{t}^{A}=i_{t}^{B}$ requires that $\left(2 h\left(s_{t}^{1}\right)+h\left(-2 s_{t}^{1}\right)\right) / 3=1 / 2$ for all values of $s_{t}^{1}$. This requires linearity in $h$ in contradiction to Condition $\Delta$. Likewise, an observed $i_{t}^{A}=i_{t}^{B}$ need not be the result of a set of signals resulting in $E\left(\eta \mid s_{t}^{1}, s_{t}^{2}, s_{t}^{3}\right)=0$. At best, the 
initial observation of aggregate investment would allow the individual investor to calculate a posterior distribution of the underlying relative value of the assets. Beliefs would then have to be updated based on continued observation of aggregate investment with the agent accounting for the evolving beliefs of the other agents as they also incorporate aggregate investment into their own beliefs. It seems implausible that such a REE could be established in practice based on the degree of dependence on the rational behavior of all of the other agents in a complex environment.

\section{Simulation}

Faced with the uncertainty in the decisions made by the other market participants and the implausibility of a REE in a generalized setting, two rule of thumb approaches to investing seem reasonable and consistent with the objectives of the rational investor in a non-rational setting. Each reflects one of the two competing investment motivations captured by $\lambda^{a}$ and $\lambda^{b}$. Fundamental investors compute the present discounted value of each project based on an estimate of when the project will be completed and its estimated value upon completion. They distribute funds based on the relative present discounted value and the confidence in their ranking. Momentum investors distribute funds between projects based on past realized returns. Both approaches are examined in simulation independently and then in a mixed market populated by both types of investors.

\subsection{Overview of the simulated model}

The simulated model starts the economy with an initial set of complete 
projects $\left(M_{0}\right)$ that produce an aggregate output $\left(D_{0}\right)$. The population of $N$ investors distribute funds between $K$ projects. Initially, each investor is an equal owner of the economy's output. Ownership of a project under development is based on the percent ownership of the outstanding shares the project has issued. Shares are purchased by investors at a price that reflects the level of development, $p_{t}^{k}=p\left(d_{t}^{k}\right)$. A project has been completed when the shadow dividend, $d_{t}^{k}$ reaches "maturity level", $d^{m}$. Upon completion, the project begins paying a dividend $D^{k}$, that is divided among investors based on ownership. Investors save at a constant savings rate, $s$. Simulation settings are provided in Table 1. 
Table 1: Simulation parameter values

\begin{tabular}{|c|c|}
\hline$D_{0}=100$ & Initial aggregate output \\
\hline$M_{0}=100$ & Initial number of productive projects \\
\hline$K=10$ & Number of projects under development at any given time \\
\hline$N=20$ & Size of investor population \\
\hline$T=500$ & $\begin{array}{l}\text { Time a which the simulation is terminated. Number of time } \\
\text { steps to reach } T \text { depends on the evolution of the market. }\end{array}$ \\
\hline$d t_{0}=1 / 20$ & Initial time-step size per iteration \\
\hline$d_{0}=0.005$ & Initial value of a new project. See price below. \\
\hline $\ln \left(D^{k}\right) \sim N(-.5,1)$ & $\begin{array}{l}\text { Contribution to output of a project upon maturity. The } \\
\text { specification produces } \mathrm{E}\left(D^{k}\right)=d^{m}=1 \text {. }\end{array}$ \\
\hline$\rho=0.05$ & Discount rate \\
\hline$s a v=s D_{t}$ & Savings, $s=.005$ \\
\hline$\delta=.05$ & $\begin{array}{l}\text { Minimum growth rate over } 50 \text { time steps to be considered } \\
\text { active }^{4}\end{array}$ \\
\hline$d_{t+1}^{k}=d_{t}^{k}+f(i)$ & $f(i)=\left((i+1)^{1-\alpha}-1\right) /(1-\alpha)$ \\
\hline$p_{t}^{k}=\max \left(d_{0}, d_{t}^{k}\right) / \rho$ & $\begin{array}{l}\text { Price determined by fundamental value. Implies perfectly } \\
\text { elastic supply of shares during the project's development. }\end{array}$ \\
\hline
\end{tabular}

Investor $n$ determines a level of investment in project $k$ based on the project's anticipated relative performance, $a_{t}^{k, n}$. The degree to which the investor is willing to concentrate his or her funds into the project with the greatest anticipated performance is based on the individual's endogenous parameter $\beta_{t}^{n}$,

$$
\omega_{t}^{k, n}=\frac{e^{\beta_{t}^{n} a_{t}^{k, n}}}{\sum_{j} e^{\beta_{t}^{n} a_{t}^{j, n}}} .
$$

\footnotetext{
${ }^{4}$ Once a project has been present for 300 time steps, the growth rate is examined. If the net growth since $t-50$ is less than $5 \%$ (i.e. $d_{t}^{k}<(1+\delta)^{*} d_{t-50}^{k}$ ), then the project is considered abandoned and a new project is introduced.
} 
The $k$ x $n$ matrix $\Omega_{t}$ contains weights for which each column sums to one. With $\beta_{t}^{n}=$ 0 , investor $n$ has no confidence in his or her ability to select which of the available projects offers the greatest return, and thus distributes funds equally between the projects, $\omega_{t}^{k, n}=1 / k$. A higher level of $\beta$ indicates a greater confidence in his or her project selecting ability, allowing for greater concentration of investment funds on the project with the greatest anticipated performance. Thus as $\beta_{t}^{n} \rightarrow \infty, \omega_{t}^{k, n} \rightarrow 1$ for the highest ranked project and $\omega_{t}^{k, n} \rightarrow 0$ for the others. Investors start the simulation tentatively with $\beta_{t}^{n}=0$. As the simulation progresses, they adjust $\beta_{t}^{n}$ to reflect the accuracy with which they select the project that realizes the greatest performance,

$$
\beta_{t}^{n}=\frac{\pi_{t}^{n}}{1-\pi_{t}^{n}} .
$$

The variable $\pi_{t}^{n}$ is a measure of the investor's past accuracy. The specific computation differs by investment strategy, so further discussion is reserved for the following two sections.

For manageability, there is no selling of shares by individuals. During the development stage shares are available from the project and are provided with perfect elasticity at the market price. The reward to ownership is realized through dividend payments once the project matures.

In simulation, the continuous time behavior is approximated by small discrete time steps. As the economy's wealth increases, the rate at which projects are completed increases as well. To accommodate, the length of each time step decreases in inverse proportion to the rate of aggregate output, $d t_{t}=d t_{0} Y_{0} / Y_{t}$. 


\section{$\underline{\text { 3.1.1 Fundamental investors }}$}

The investor receives a signal, $y_{t}^{k, n}$ as defined in (8). The investor estimates $D^{k}$ based on the received private signals:

$$
E_{t}^{n}\left(\ln \left(D^{k}\right)\right)=\left(1-\gamma_{t}^{k}\right) \mu+\gamma_{t}^{k} \bar{y}^{k, n}
$$

where $\bar{y}^{k, n}$ indicates the mean of the signals investor $n$ has received on project $k$ and

$$
\gamma_{t}^{k}=\frac{\sigma_{\varepsilon}^{2}}{\sigma_{\varepsilon}^{2}+\sigma_{e}^{2} / l k}
$$

The divisor $l k$ is the number of signals received concerning the value of project $k$. Trader $n$ thus expects project $k$ to have a maturity value of

$$
E_{t}^{n}\left(D^{k}\right)=\exp \left(E_{t}^{n}\left(\ln \left(D^{k}\right)+V_{t}^{n}\left(\ln \left(D^{k}\right)\right) / 2\right)\right.
$$

where $V_{t}^{n}\left(\ln \left(D^{k}\right)=\gamma_{t}^{k} \sigma_{e}^{2} / l k\right.$

To compute the present discounted value, each investor also models project development over time. The model provides a forecast of the completion date that the investor uses to discount the value of each project. Each project is assumed by the investors to grow at a rate that is dependent on its rank by size. The project of rank $r\left(r=1\right.$ indicating the smallest project) grows at rate $\theta_{r}, d_{t+1}^{r}=\left(1+\theta_{r}\right) d_{t}^{r}$. The investors estimate these growth rates based on historical data generated by the simulation. Investors compute the estimates $\theta_{r}$ by estimating the $b_{r}$ coefficients of the transition equation

$$
d_{t+1}^{k}=\left(1+b_{1}\right) d_{t}^{k}+\sum_{i=2}^{k} b_{i}\left(d_{t}^{k} x_{t}^{i, k}\right) .
$$

From these, $\theta_{r}=\sum_{i=1}^{r} b_{i}$. The variable $x_{t}^{i, k}$ is a dummy that takes a value of 1 if the 
rank of a project is less than or equal to $i$. The coefficients are updated during the course of the simulation according to a least-squares learning algorithm. (See Marcet and Sargent 1989.)

The model produces a time to completion estimate

$$
\hat{\tau} k=\ln \left(d^{m} / d_{t}^{k}\right) / \ln \left(\theta_{K}\right)
$$

for the next project to mature. The subsequent $K-1$ projects are forecast to mature at

$$
\hat{\tau}(k+j)=\hat{\tau}(k+j-1)+\frac{\ln \left(d^{m} /\left(d_{t}^{k+j} \prod_{i=1}^{j-1}\left(\theta_{K-i}\right)^{\tau i}\right)\right)}{\ln \left(\theta_{K}\right)} \text { for } 2 \leq j \leq K .
$$

The fundamental investors estimate the present value of each project as

$$
v_{t}^{n, k}=e^{-\rho \hat{\tau} k} E_{t}^{n}\left(D^{k}\right) / \rho .
$$

As an input to (15), relative performance across projects is normalized according to

$$
a_{t}^{n, k}=\left(v_{t}^{n, k}-\bar{v}_{t}^{n}\right) / s v_{t}^{n} .
$$

Here, $\bar{v}_{t}^{n}$ and $s v_{t}^{n}$ are the sample mean and standard deviation of estimated performance across projects as measured by investor $n$ in period $t$.

Fundamental traders update their individual $\beta_{t}^{n}$ each time a project matures. Success for a fundamental investor is measured by whether the project he or she believed to be the highest present valued project during the course of development turned out to have the highest present value. Each time a project matures the investors rank the existing projects, including the one that just matured, using $E\left(D^{k}\right)\left(d_{t}^{k} / d^{m}\right)$ as the value at time $t k$. The recently matured project need not be the 
highest ranked project. Let $\kappa_{t k}$ represent the proportion of the time steps between $t(k$ 1) and $t k$ in which the investor correctly chose the project with the highest valuation at time $t k$. The value of $\pi$ is updated according to equation

$$
\pi_{t(k)}^{n}=\pi_{t(k-1)}^{n}+\left(\kappa_{t k}-\pi_{t(k-1)}^{n}\right) / \tau k .
$$

The investors are not social planners. They evaluate their performance based on the market outcome. Whether the market did a good job in selecting which project to develop is beyond the individual investor's control and is not a component of his or her performance measure.

\subsubsection{Momentum investors}

The momentum investors attempt to select the project offering the highest one period ahead return,

$$
r e t_{t}^{k}=\ln \left(p_{t}^{k}\right)-\ln \left(p_{t-1}^{k}\right) .
$$

Investors received private information $z_{t}^{n, k} \sim N(0,1)$. The momentum investors index value based on $E\left(\right.$ ret $\left._{t+1}\right)$,

$$
v_{t}^{n, k}=E_{n}\left(r e t_{t+1}^{k}\right)=c_{0}+c_{1} r e t_{t}^{k}+c_{2} d_{t}^{k}+c_{3} z_{t}^{n, k} .
$$

The coefficients are updated according to the standard least-squares learning algorithm with initial values set to zero.

The momentum investors measure success each period by whether they correctly selected the project with the highest realized paper returns. Thus, for the momentum investors $\pi_{t}$ is the proportion of periods in which the project producing the highest return is correctly identified. There is a disconnect between perceived investment success and the realization of returns since the measured performance depends on paper return that may never be realized. 


\subsection{Simulation results}

Simulations 1 and 2 are populated by fundamental investors. Simulation 3 is populated by momentum investors. Simulations 4 and 5 are populated by a mix of both investor types. The mean and population standard deviation of basic economic performance and the investor accuracy are reported in Table 2. The data are generated from 100 iterations based on independent draws of project values. Each simulation is applied to the same set of 100 series of realizations. The figures that follow display the results of a single typical simulation outcome (iteration run number 5).

Table 2: Accuracy and economic performance Averages and standard deviations (in parenthesis) of economic performance measures. 100 iterations of each simulation. Each simulation set is based on the same 100 series of randomly determined projects.

\begin{tabular}{|c|c|c|c|c|c|c|c|}
\hline \multirow[b]{2}{*}{ Sim } & \multirow[b]{2}{*}{ Description } & \multirow{2}{*}{$\begin{array}{c}\text { Associated } \\
\text { Figures }\end{array}$} & \multicolumn{2}{|c|}{ Accuracy } & \multirow[b]{2}{*}{$D_{T}$} & \multirow[b]{2}{*}{$M_{T}$} & \multirow{2}{*}{$\begin{array}{l}\text { Momentum } \\
\text { Ownership }\end{array}$} \\
\hline & & & $\mathrm{F}$ & $M$ & & & \\
\hline 0 & Base & --- & $\begin{array}{l}-- \\
---\end{array}$ & $\begin{array}{l}-- \\
---\end{array}$ & $\begin{array}{r}1293.43 \\
(160.70)\end{array}$ & $\begin{array}{l}1287.01 \\
(124.19)\end{array}$ & $\begin{array}{l}-- \\
---\end{array}$ \\
\hline 1 & $\begin{array}{l}\text { Fundamental } \\
\text { noise-free signal }\end{array}$ & $1,2,3$ & $\begin{array}{r}0.9988 \\
(0.0012) \\
\end{array}$ & --- & $\begin{array}{r}6020.71 \\
(1033.28) \\
\end{array}$ & $\begin{array}{l}3619.86 \\
(586.29) \\
\end{array}$ & --- \\
\hline 2 & $\begin{array}{l}\text { Fundamental } \\
\text { noisy signal, } \sigma(e)^{2}=100\end{array}$ & 4,5 & $\begin{array}{r}0.6257 \\
(0.0107) \\
\end{array}$ & $\begin{array}{l}-- \\
--- \\
\end{array}$ & $\begin{array}{l}2534.01 \\
(441.16) \\
\end{array}$ & $\begin{array}{l}1937.60 \\
(297.17) \\
\end{array}$ & $\begin{array}{l}-- \\
--- \\
\end{array}$ \\
\hline 3 & Momentum & 6,7 & $\begin{array}{l}-- \\
--- \\
\end{array}$ & $\begin{array}{r}0.9815 \\
(0.0018) \\
\end{array}$ & $\begin{array}{r}140.62 \\
(169.23) \\
\end{array}$ & $\begin{array}{r}142.11 \\
(174.09) \\
\end{array}$ & $\begin{array}{l}-- \\
--- \\
\end{array}$ \\
\hline 4 & $\begin{array}{l}\text { Both } \\
\text { noise-free signal }\end{array}$ & 8,9 & $\begin{array}{r}0.9420 \\
(0.0415) \\
\end{array}$ & $\begin{array}{r}0.9639 \\
(0.0121) \\
\end{array}$ & $\begin{array}{l}3492.08 \\
(905.13) \\
\end{array}$ & $\begin{array}{l}2206.66 \\
(588.19) \\
\end{array}$ & $\begin{array}{r}0.3647 \\
(0.0281) \\
\end{array}$ \\
\hline 5 & $\begin{array}{l}\text { Both } \\
\text { noisy signal, } \sigma(e)^{2}=100\end{array}$ & ---- & $\begin{array}{r}0.3925 \\
(0.0274) \\
\end{array}$ & $\begin{array}{r}0.9792 \\
(0.0112) \\
\end{array}$ & $\begin{array}{r}989.34 \\
(157.33) \\
\end{array}$ & $\begin{array}{l}616.21 \\
(75.74) \\
\end{array}$ & $\begin{array}{r}0.6046 \\
(0.0132) \\
\end{array}$ \\
\hline 6 & $\begin{array}{l}\text { Fundamental } \\
\delta=0.2, \sigma(e)^{2}=10\end{array}$ & ---- & $\begin{array}{r}0.8021 \\
(0.0043)\end{array}$ & --- & $\begin{array}{l}4088.11 \\
(671.64)\end{array}$ & $\begin{array}{r}2732.87 \\
(411.3176) \\
\end{array}$ & $\begin{array}{l}-- \\
---\end{array}$ \\
\hline 7 & $\begin{array}{l}\text { Both } \\
\delta=0.2, \sigma(e)^{2}=10\end{array}$ & 10 & $\begin{array}{r}0.6092 \\
(0.0068) \\
\end{array}$ & $\begin{array}{r}0.9535 \\
(0.0077) \\
\end{array}$ & $\begin{array}{l}3566.11 \\
(542.50)\end{array}$ & $\begin{array}{l}2243.40 \\
(303.40) \\
\end{array}$ & $\begin{array}{r}0.2273 \\
(0.0111) \\
\end{array}$ \\
\hline
\end{tabular}

\subsubsection{Simulations with fundamental investors}

Simulation 0 establishes a base level of performance. A single project is developed without knowledge of its maturity value. This is equivalent to 
development under a central planner who can coordinate investing but does not have access to information signaling $D^{k}$. The fact that $D_{T}$ and $M_{T}$ are approximately equal is a reflection of the failure to select projects based on maturity value.

In comparison to the base case, developing the same set of projects simultaneously results in a smaller number of mature projects producing less output. On average, sequential development produces 47 more projects by the end simulation than does simultaneous development. The minimum difference over the 100 runs is 35 additional projects produced by sequential development.

For the first set of simulations $\sigma_{e}$ is set to zero so that the investors receive a perfect signal about the value of each project upon completion. The investing behavior of the other market participants is thus the only source of uncertainty. Figure 1 plots the values of $\theta_{r}, r=1, \ldots K$, during the course of the simulation. The figure shows that the smallest project maintains a growth rate of about $2.5 \%$ while, initially, all other projects attain nearly zero growth. ${ }^{5}$ Over the course of the simulation the investors learn to favor the largest project, which becomes reflected in the rise of the largest project's estimated growth rate. Towards the end of the sample, projects that are well-developed grow quickly, reinforcing the learning. Investors quickly learn to invest in the most promising projects; and thus any well developed project is one that the market has determined to have high value upon completion. The benefit to aggregate performance derived from the ability to select projects is reflected in $D_{T}>M_{T}$.

The top frame of Figure 2 plots the time-series of $d_{t}^{k}$ for each project taken

\footnotetext{
${ }^{5}$ The high growth rate in the smallest project reflects the greater percent change induced by a small rate of investment rather than an indication of a high rate of investment. Maintaining growth in a large project requires greater investment.
} 
from the first 1000 time steps of the simulation. The level of development of the initial 10 projects is determined randomly. The lower frame plots the $D^{k}$ for each project (the vertical axis is a $\log$ scale). The learning process and the increased confidence in the investor's ability to predict can be seen in these early periods as the investors increasingly concentrate their funding towards the project with the greatest $D^{k}$. Figure 3 plots the same information for the last 1000 time steps of the simulation. In the late periods, investors are confident about their ability to select correctly which project to invest in. In all of the simulations, long dormant projects are cleared to allow replacement by a new undeveloped project. This clearing prevents projects that are not of interest to the investors from crowding out the introduction of new projects.

Simulation 2 sets $\sigma_{e}^{2}=100$. In this noisy signal version of the model, investors possess heterogeneous information about which project has the greatest value. Because these errors tend to average out, the market still tends to develop the correct project, but individual investors experience errors in project selection, resulting in a lower $\beta$ and thus less concentration of investment funds.

Figure 4 reveals the inability of the investors to coordinate investing efforts on a single project. Figure 5 reveals that the investors end up developing clusters of projects. Low individual confidence results in a distribution of funds across projects. The highest valued project attracts the greatest level of investment and grows the fastest, but other projects also receive funding.

\subsubsection{Simulations with momentum investors}

Simulation 3 is based on a market populated by momentum investors. Figure 
6 displays the initial learning and confidence building of the investors as they correctly select the project offering the highest returns. Momentum investors are attracted to two features in a project, a high rate of development (momentum) and a low level of development. Momentum serves as a coordinating device, offering high returns as a result of growth. Less developed projects offer greater returns for the same rate of investment making them more attractive than a more developed project receiving equal funding. One pattern to emerge from the particular parameter settings of simulation 3 is that the benefit of momentum in a mature project is insufficient to maintain interest in the project through to completion. The robustness of this outcome is discussed in Section 3.2.4. Investors become attracted to immature projects offering high returns despite their low investment. Plotting series produced near the end of the simulation, Figure 7 shows a pattern of investing that produces pools of stagnant projects, many of which become dormant before completion.

Table 2 reports that on average about 140 projects are developed during the sample run. There is a substantial waste of resources in repeatedly developing projects only to have them become dormant. Somewhat perversely, the great accuracy of the momentum strategy in predicting one period ahead paper returns compounds the problem by giving the momentum investors great confidence.

\subsubsection{Simulations with mixed population strategies}

The markets in simulations 4 and 5 are initiated with an equal number of investors of both types. Simulation 4 is based on the fundamental investors receiving a noise free signal of the maturity value while simulation 5 has the same investors receiving a noisy signal. Ownership of the economy's output is initially evenly divided between the two groups, but evolves according to the ownership of the 
matured projects.

As reported in Table 2, the momentum investor's percent ownership of the economy's resources declines during the course of the simulation, averaging about $36 \%$ at termination. Figure 8 displays the $\theta_{r}$ values, and Figure 9 adds a new frame to the basic time-series figure, separately displaying $i^{k}$ for each trader type.

The inferior relative performance of the momentum investors and the overall reduced aggregate performance of the market relative to simulation 1 is attributable to the momentum investors' project selection and abandonment. Though the fundamental investors are a social planner's obvious choice for selecting which projects to develop next, they are also motivated to complete projects that are already developed. The momentum investors' attraction to young projects means they initiate investment in the market's next project. Often they abandon these projects before completion. Low valued, partially developed projects typically do not attract the fundamental investors who instead choose a high maturity value project from the undeveloped pool. The development and abandonment of low valued projects results in the waste of the economy's resources.

Even though they are a detriment to the economy, momentum investors have the potential to outperform the fundamental investors. Investing in young projects means that ownership is acquired cheaply. When the momentum investors happen upon a high quality project, the fundamental investors develop the project to maturity. The low value of ownership reported in Table 2 suggests that on average the momentum traders lose more through waste than they gain from early investment, but this outcome is reversed in some runs of simulation 4. Adding noise to the 
fundamental trader signal reverses this outcome, as found in simulation 5.

As revealed by simulation 2 , noise in the signals hampers the ability of the fundamental investors as a group to settle confidently on a single project to develop. Mixing the momentum investors with the fundamental investors has the potential to improve economic performance when the fundamental investors receive noisy information. Though the individual fundamental investors possess heterogeneous information on the value of each project, aggregation filters the errors, leaving observed returns as a reasonable indicator of the consensus best project. The momentum investors can then facilitate coordination by investing on the project earning the highest return.

Unfortunately, behavior in simulation 5 does not match this idealized potential. As can be seen in Figure 4, while coordination helps the investors to pick out the highest value project, the highest returns are still realized by the least developed project. The momentum investors fail to follow the lead of the fundamental investors. The momentum investors end up determining which project to initiate investment through their ability to coordinate on the least developed project. With the fundamental investors receiving noisy information, all projects are developed through to completion so the momentum strategy is not hampered by its own lack of follow through. The presence of the fundamental investors improves the performance of the momentum investors. Aggregate output is extremely low relative to simulation 2 but an improvement over simulation 3 .

No parameter values examined were able to produce an environment in which the presence of the momentum investors improved performance relative to a market 
populated exclusively by fundamental investors. Simulations 6 and 7 are based on a market environment that favors initial project selection by fundamental investors. This is accomplished by setting $d_{0}$ to 0.2 and $\sigma_{e}^{2}$ to 10 so that new projects no longer offer high returns. Simulation 6 has only the fundamental investors while simulation 7 is populated by both types. The market in simulation 7 evolves to the point at which the momentum investors, follow the lead of the fundamental investors but economic performance still suffers relative to simulation 6 . The momentum investors continue to abandon projects prior to completion in order to invest in younger projects. This behavior disrupts the market sufficiently so that the fundamental investors suffer low accuracy. The low accuracy ensures a modest level of development of even the low valued projects. Figure 10 reveals the market's inability to coordinate to produce growth in the most mature projects. On the other hand, the fundamental investors benefit from the presence of the momentum investors. Though the economy from simulation 7 is smaller than that produced by simulation 6 , it is better to own $1 / 10$ of the fundamentalists' $78 \%$ share of the economy produced by simulation 7 than to own $1 / 20$ of the economy produced by simulation 6 .

\subsubsection{Robustness of the simulation results}

Two parameters that strongly influence the nature of the investment market in simulation are $d_{0}$ and $\delta$.

If $d_{0}$ is set sufficiently high, then momentum investors remain focused on developing a single project through to completion. Selection remains arbitrary so that the momentum investors match the base case level of economic performance. If the fundamental investors are also present, they may be able to lead project selection 
as in simulation 7 .

Set $\delta$ low, and unattractive projects remain active but undeveloped, blocking the introduction of new projects. The fundamental investors' ability to discern between projects becomes moot due to the formation of a pool of low valued projects. Performance by the fundamental investors is reduced to match the base case. With both investor types present, the lower $\delta$ allows the momentum investors to grow to dominate the market quickly. The fundamental investors are reduced to selecting the best project from the pool of partially developed projects.

\section{Conclusion}

The solution to the central planner's problem demonstrates that concentrating the economy's resources on a single project is superior to distributing the economy's resources among a large number of projects. This result is true whether or not there is uncertainty in the value of the project upon completion. In a decentralized market, individual investors face greater uncertainty in their investment decision than the central planner due to the uncertainty associated with the investment decisions of the other investors.

In simulation, exclusive use of either fundamental or momentum strategies produces coordination among the population of traders. The fundamental approach works well in coordinating investment on high valued projects and developing those projects to completion. Noisy private signals diminish economic performance. The investors lack the confidence to invest exclusively in the project with the greatest value. The momentum investors are very good at coordinating, since they are all acting on the same information, but develop an investment pattern that fails to 
develop the economy. Partially developed projects become dormant due to investors' abandonment as they become distracted by the small gains, but high growth rate, offered by less developed projects.

The fundamental investors tend to outperform the momentum investors in simulations populated by both types when they receive sufficiently accurate private signals. The momentum investors tend to perform well relative to the fundamental investors when the private signals are noisy. In both cases, the presence of the momentum investors disrupts the learning process of the fundamental investors, hampering their ability to develop the economy successfully. Further, the relative success of a strategy that produces the inferior outcome suggests that markets are not always capable of rewarding good investment strategies.

\section{Appendix}

\section{A.1 Further discussion of the optimal investment path for the central planner}

The solution expressed in (4) characterizes the optimal consumption stream, $t k$ to $t(k+1)$. A closed form solution to the optimal path is not solved. The standard optimal control problem has a salvage value that is exogenous or endogenous to the terminal value of the state variable. The value of $V\left(\mathbf{d}_{t k}\right)$ on the RHS of (4) is endogenous to the consumption/investment decision made in $t>t k$, and thus it fails to establish a fixed endpoint condition to the problem expressed in (3). Since the optimal decision rule expressed in (4) holds for each of the subsequent projects, the problem is again recursive. Let 


$$
X\left(c_{t k}^{-}, k\right)=\int_{t(k-1)}^{t(k)} e^{-\rho t} u\left(c_{t}^{*}\right) d t
$$

indicate the present discounted value of the stream of utility derived during the endogenously determined period $t(\mathrm{k}-1)$ and $t(\mathrm{k})$ along the optimal consumption path. Given that $c_{t k}^{*_{-}}$anchors the remainder of the consumption path, $c_{t}^{*}$, the economy selects $c_{t k}^{{ }^{-}}$optimally to maximize

$$
V\left(\mathbf{d}_{0}\right)=\sum_{k=1}^{\infty} X\left(c_{t k}^{-}, k\right) .
$$

\section{A.2 Proof of Proposition 1}

The LHS of (4) captures the marginal cost of reducing consumption in order to invest in project $k$. Concavity in $u$ ensures that increasing total investment increases costs, regardless of which project is being financed. The return to investment, $f$, is either linear or concave. If concave, then heavy investment in a single project increases the marginal cost of investing in that project without affecting the cost of the other projects. The concavity of $u$ and $f$ ensure that the marginal cost of investing is increasing and convex in $i_{t}$ though individual projects face different costs that are increasing in the rate of investment, $i_{t}^{k}$.

The RHS of (4) captures the marginal benefit. Investment in project $k$ brings the project closer to completion by changing $t k$ in the discounting of the RHS. The value upon completion is constant. The marginal benefit to increasing investment in project $k$ is increasing but concave. The maximum benefit is achieved when all the 
economy's output is used on project $k$ 's development. ${ }^{6}$ For $i_{t}^{j} \leq i_{t}^{k}$, the increasing marginal benefit ensures that diverting resources away from project $j$ towards project $k$ improves utility.

For linear $f$ it is optimal to direct investment resources to a single project. Concavity in $f$ can attenuate this by increasing the marginal cost at high levels of investment in a single project. If this is the case, then investment may optimally be directed towards a secondary (tertiary, etc.) project for which the lower marginal cost compensates for the lower marginal benefit.

\section{References}

Arifovic J, Masson P., 2004. Heterogeneity and evolution of expectations in a model of currency crisis. Nonlinear Dynamics, Psychology, and Life Sciences 8, 231257.

Banerjee AV., 1992. A simple model of herd behavior. Quarterly Journal of Economics 107, 797-817.

Barberis N, Shleifer A., 2003. Style investing. Journal of Financial Economics 68, 161-199.

Bikhchandani S, Hiershleifer D, Welch I., 1992. A theory of fads, fashion, custom, and cultural change in informational cascades. The Journal of Political Economy $100,922-1026$.

Calvo GA, Mendoza EG., 1996. Mexico's balance-of-payments crisis: a chronicle of a death foretold. Journal of International Economics 41, 235-264.

\footnotetext{
${ }^{6}$ If the economy's resources were unlimited, then the RHS converges to $\left(\rho V\left(\mathbf{d}_{t k}\right)-u\left(c_{t k}^{-}\right)\right) / f\left(i_{t k}^{-}\right)$as $i_{t}^{k} \rightarrow \infty$.
} 
Caplin A, Leahy J., 1994. Business as usual, market crashes, and wisdom after the fact. The American Economic Review 84, 548-565.

Chari VV, Kohoe PJ., 2003. Hot money. Journal of Political Economy 111, 12621292.

Claessens S, Klingebiel D, Schmukler S., 2003. Government bonds in domestic and foreign currency: the role of macroeconomic and institutional factors. World Policy Research Bank Working Paper 2986.

DeLong JB, Shleifer A, Summers LH, Waldmann RJ., 1990. Positive feedback investment strategies and destabilizing rational speculation. Journal of Finance 45, 379-395.

Dixit A, Mirrlees J, Stern N., 1975. Optimum saving with economies of scale. Review of Economic Studies 42, 303-325.

Dollar D., 2002. Reform, growth, and poverty in Vietnam. World Bank Policy Research Working Paper 2837.

Froot KA, O'Connell PGJ, Seasholes MS., 2001. The portfolio flows of international investors. Journal of Financial Economics, 59, 151-193.

Froot KA, Scharfstein DS, Stein JS., 1992. Herd on the street: informational inefficiencies in the market with short-term speculation. The Journal of Finance $47,1461-1484$.

Grais W, Kantur S., 2003. The changing financial landscape: opportunities and challenges for the Middle East and North Africa. World Bank Policy Research Working Paper 3050.

Hirshleifer D, Subrahmanyam A, Titman S., 1994. Security analysis and trading 
patterns when some investors receive information before others. The Journal of Finance 49, 1665-1698.

Hong H, Stein JC., 1999. A unified theory of underreaction, momentum trading, and overreaction in asset markets. The Journal of Finance 54, 2143-2184.

Lucas RE., 1978. Asset prices in an exchange economy. Econometrica 46, 14261445.

Marcet A, Sargent TJ., 1989. Convergence of least squares learning mechanisms in self-referential linear stochastic models. Journal of Economic Theory 48, 337368.

Meigas H., 2001. Using development oriented equity investment as a tool for restructuring transition banking sectors. World Bank Policy Research Working Paper 2723.

Moretto M., 2000. Irreversible investment with uncertainty and strategic behavior. Economic Modeling 17, 589-617. 
Figure 1: Evolution of $1+\theta_{r}$, fundamental investors only. Simulation 1, run $\# 5$.

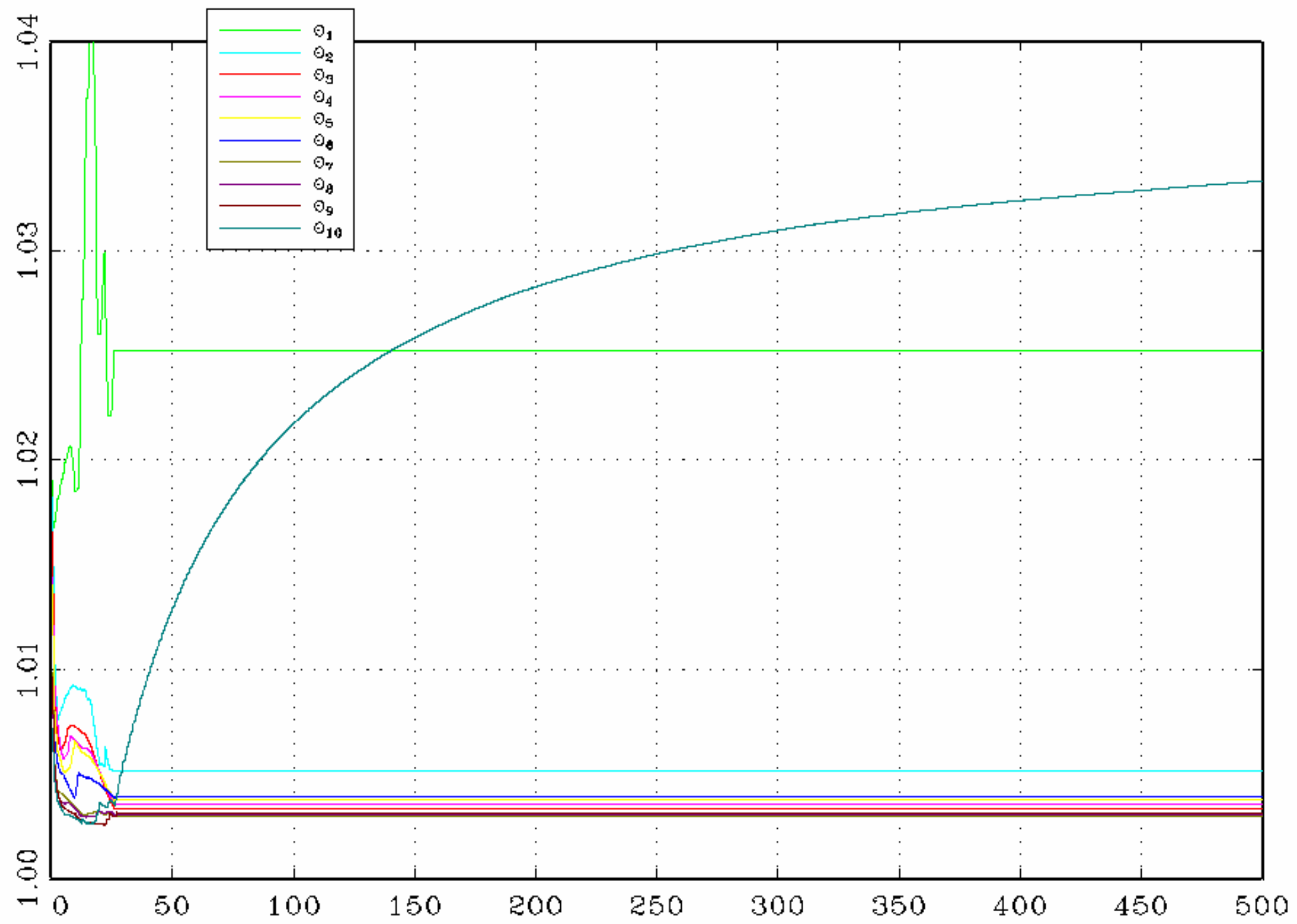


Figure 2: Time-series of $d_{t}^{k}, i_{t}^{k}, D^{k}$, first 1000 time-steps, fundamental investors only. Simulation 1, run \#5.
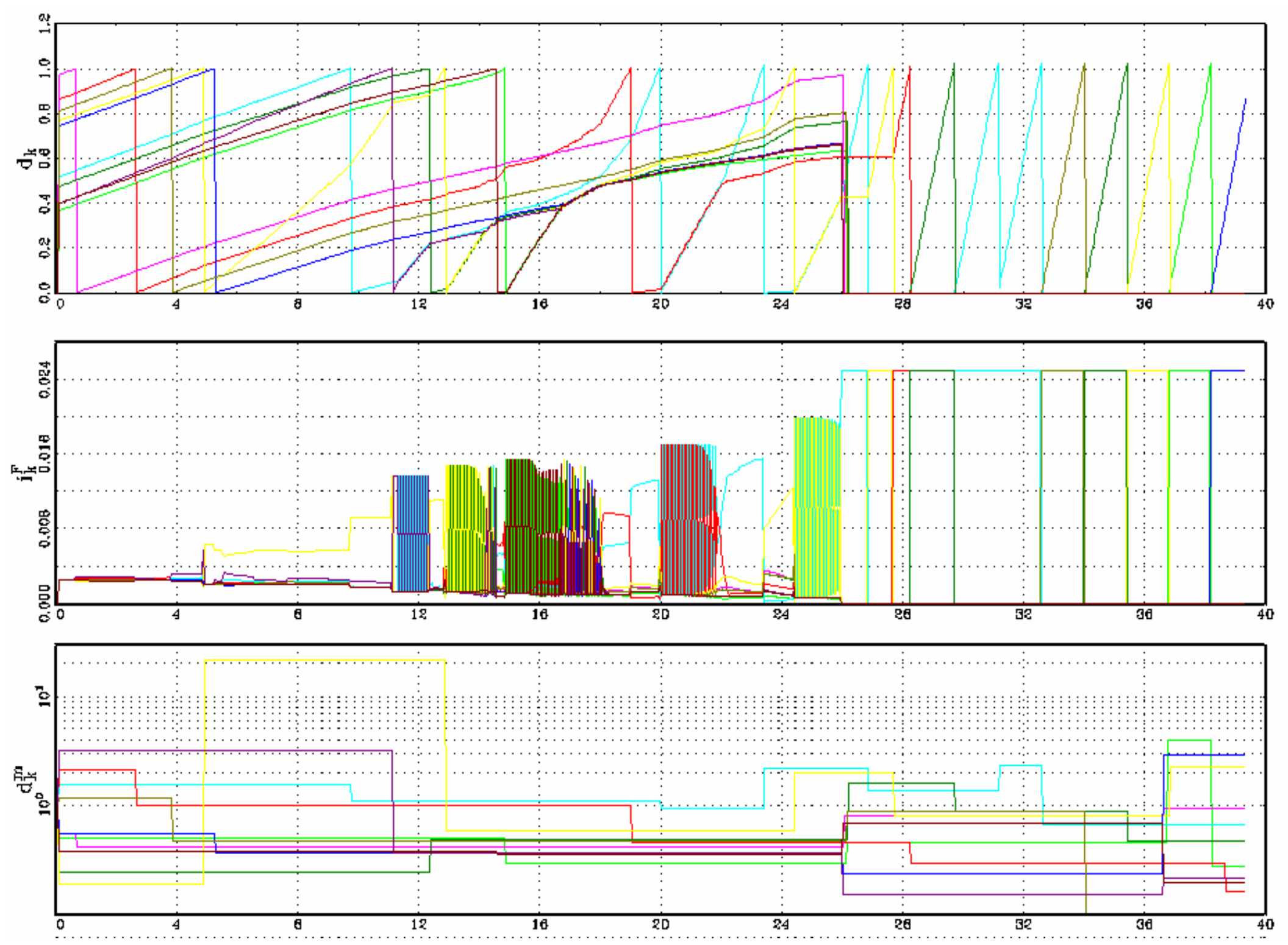
Figure 3: Time-series of $d_{t}^{k}, i_{t}^{k}, D^{k}$, last 1000 time-steps, fundamental investors only. Simulation 1, run \#5.
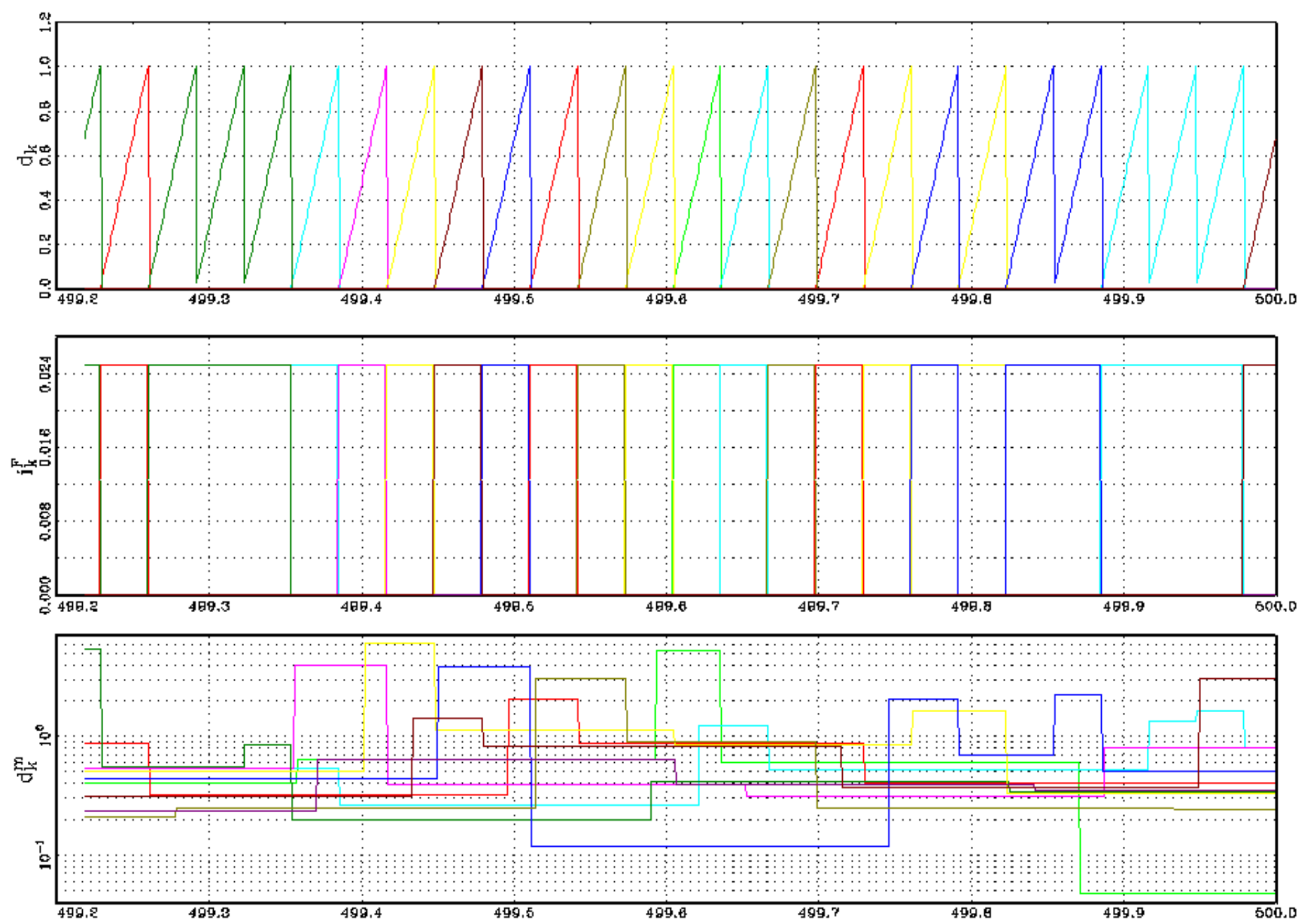
Figure 4: Evolution of $1+\theta_{r}$, fundamental investors with noisy signal. Simulation 2, run \#5.

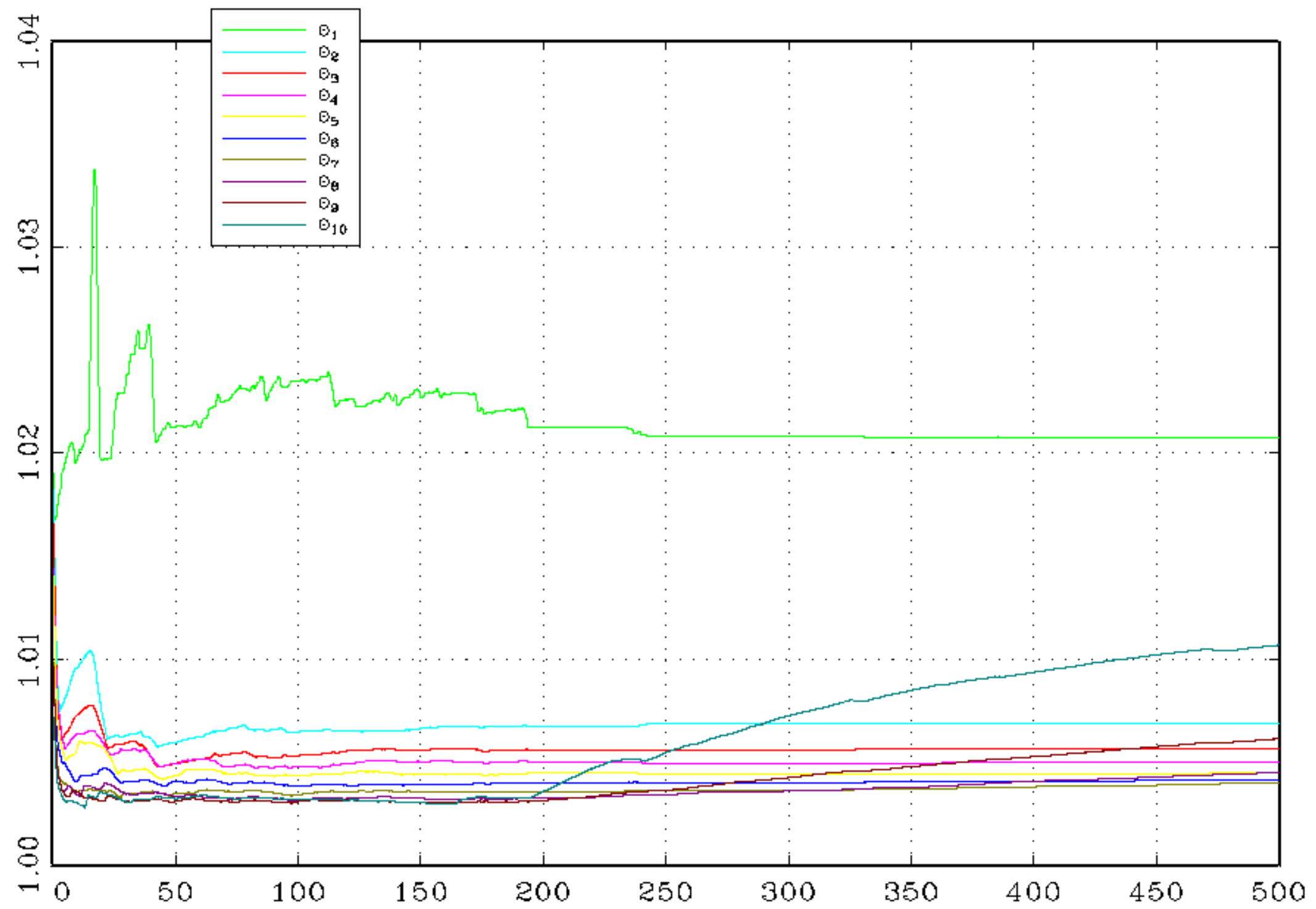


Figure 5: Time-series of $d_{t}^{k}, i_{t}^{k}, D^{k}$, last 1000 time-steps, fundamental investors only with noisy signal. Simulation 2 , run \#5.
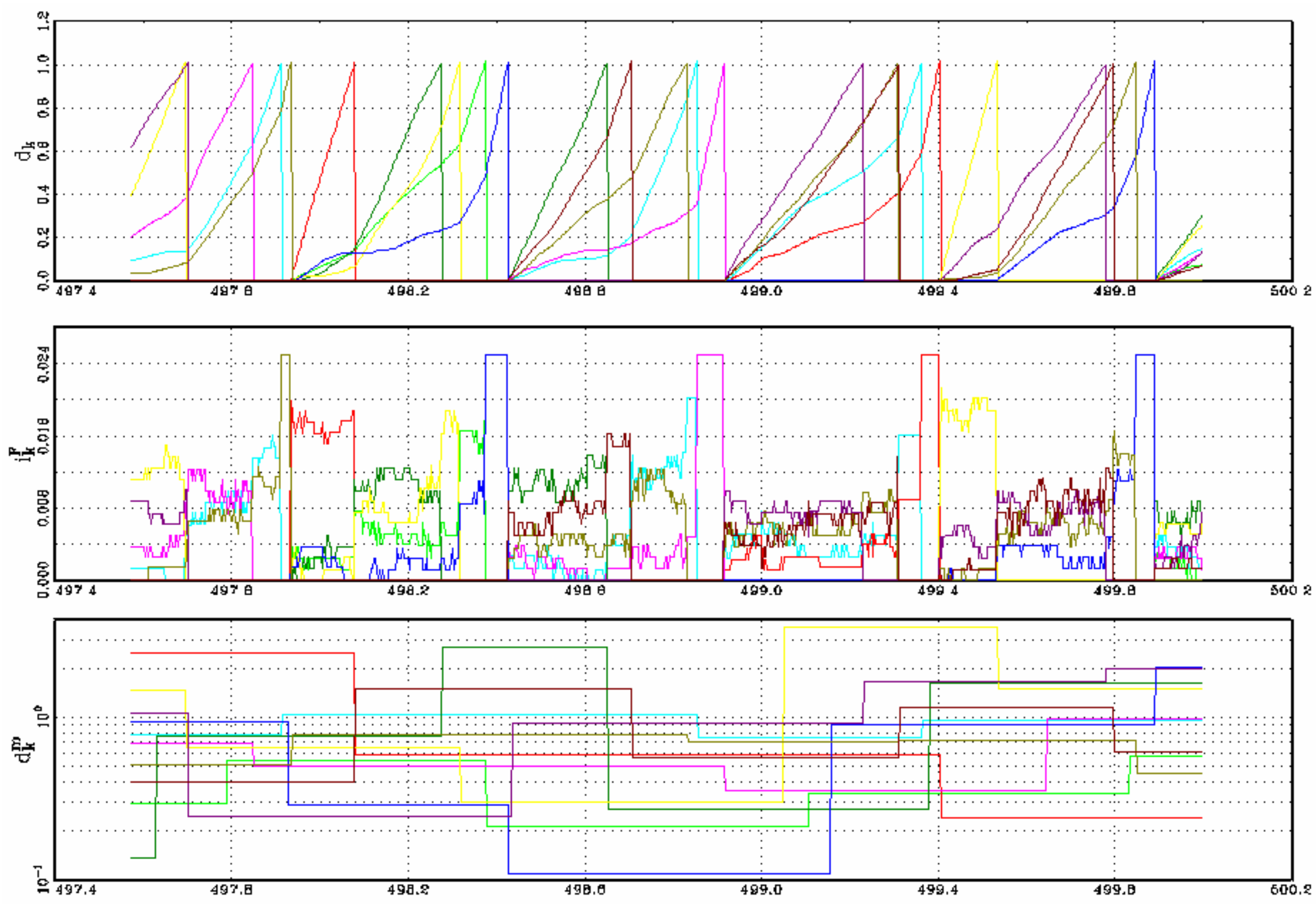
Figure 6: Time-series of $d_{t}^{k}, i_{t}^{k}, D^{k}$, first 1000 time-steps, momentum investors only. Simulation 3, run \#5.
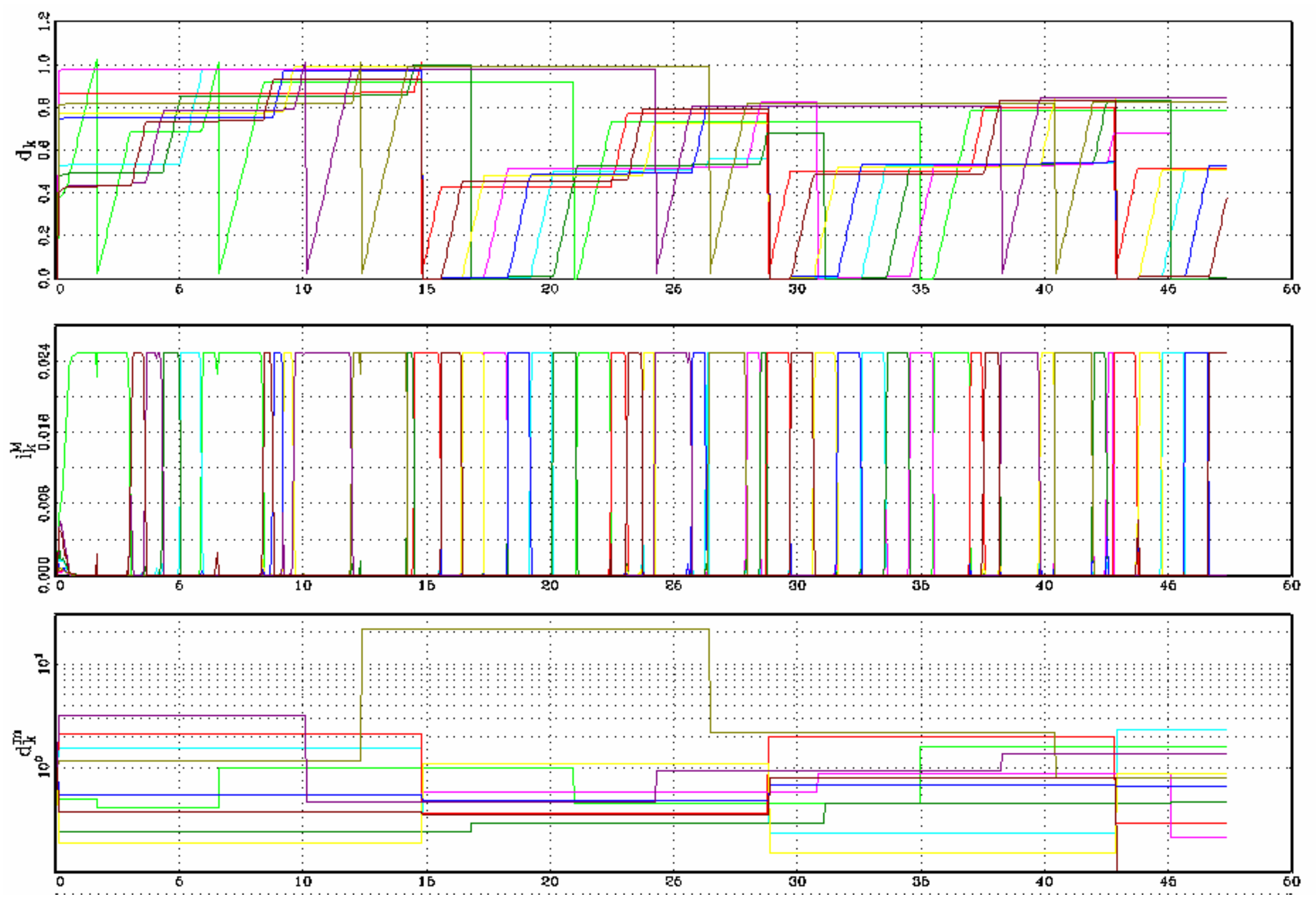
Figure 7: Time-series of $d_{t}^{k}, i_{t}^{k}, D^{k}$, last 1000 time-steps, momentum investors only. Simulation 3, run \#5.
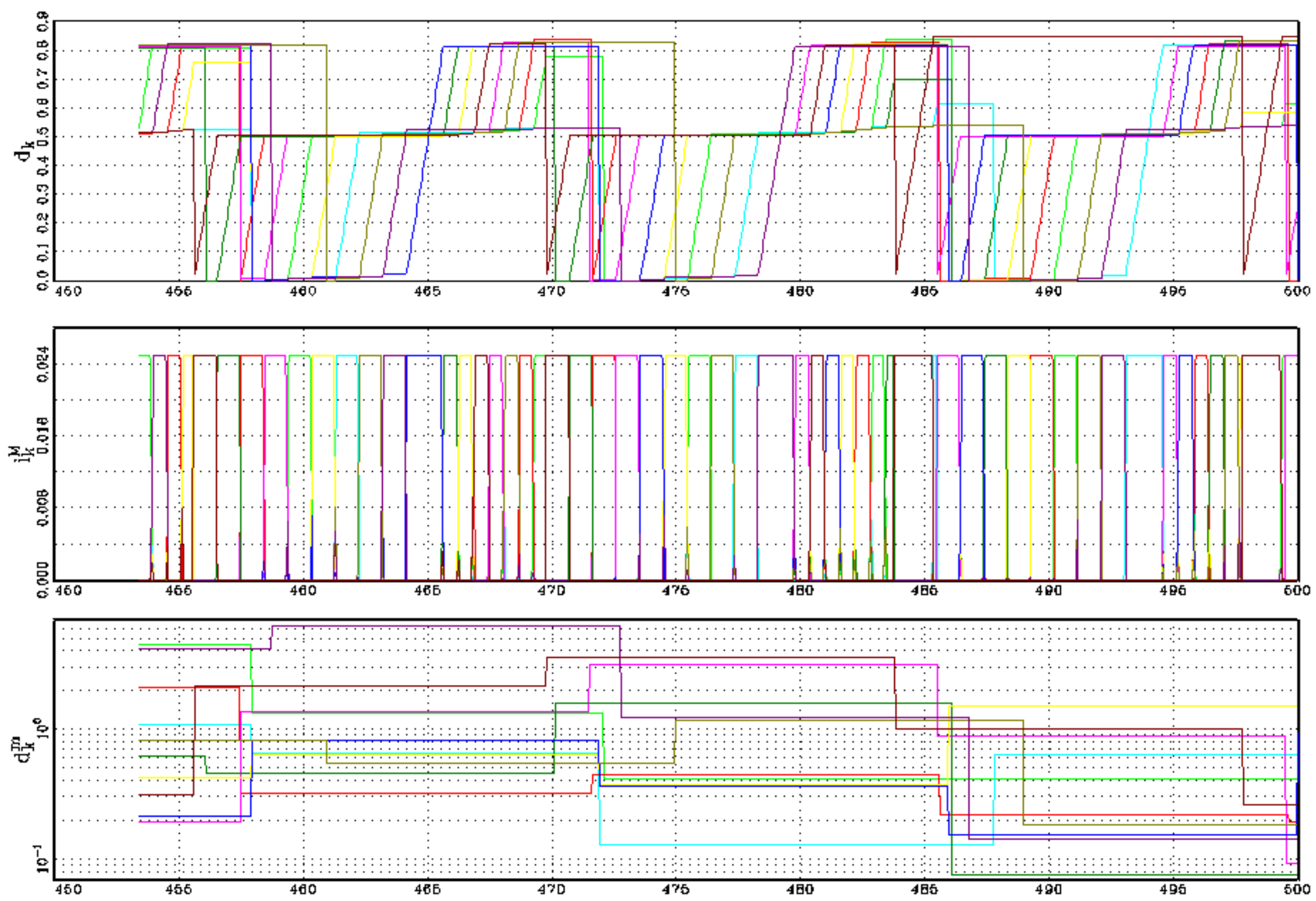
Figure 8: Evolution of $1+\theta_{r}$, fundamental and momentum investors. Simulation 4, run \#5.

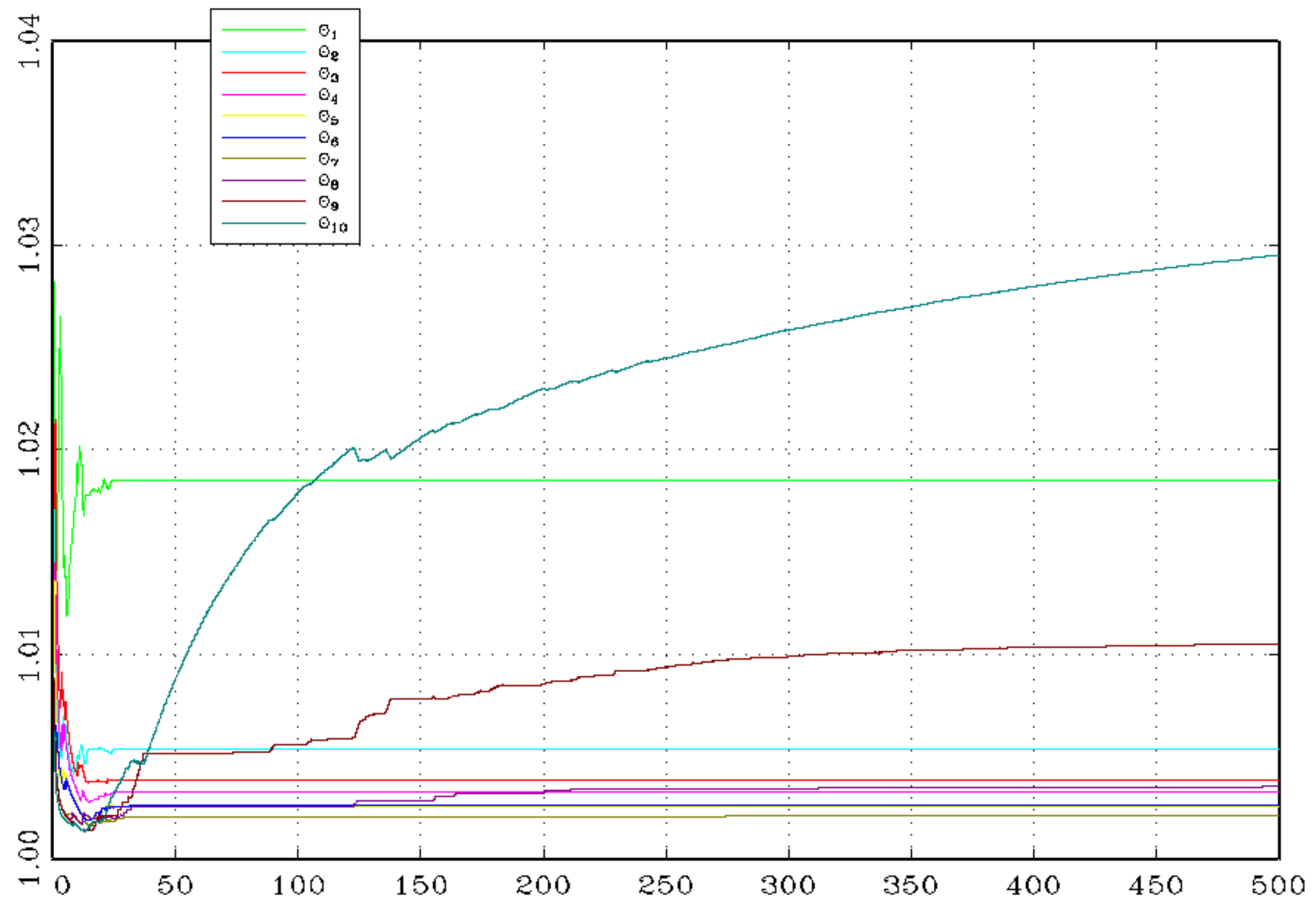


Figure 9: Time-series of $d_{t}^{k}, i_{t}^{k}(\mathrm{M}), i_{t}^{k}(\mathrm{~F}), D^{k}$, last 1000 time-steps, fundamental and momentum investors. Simulation 4, run \#5.
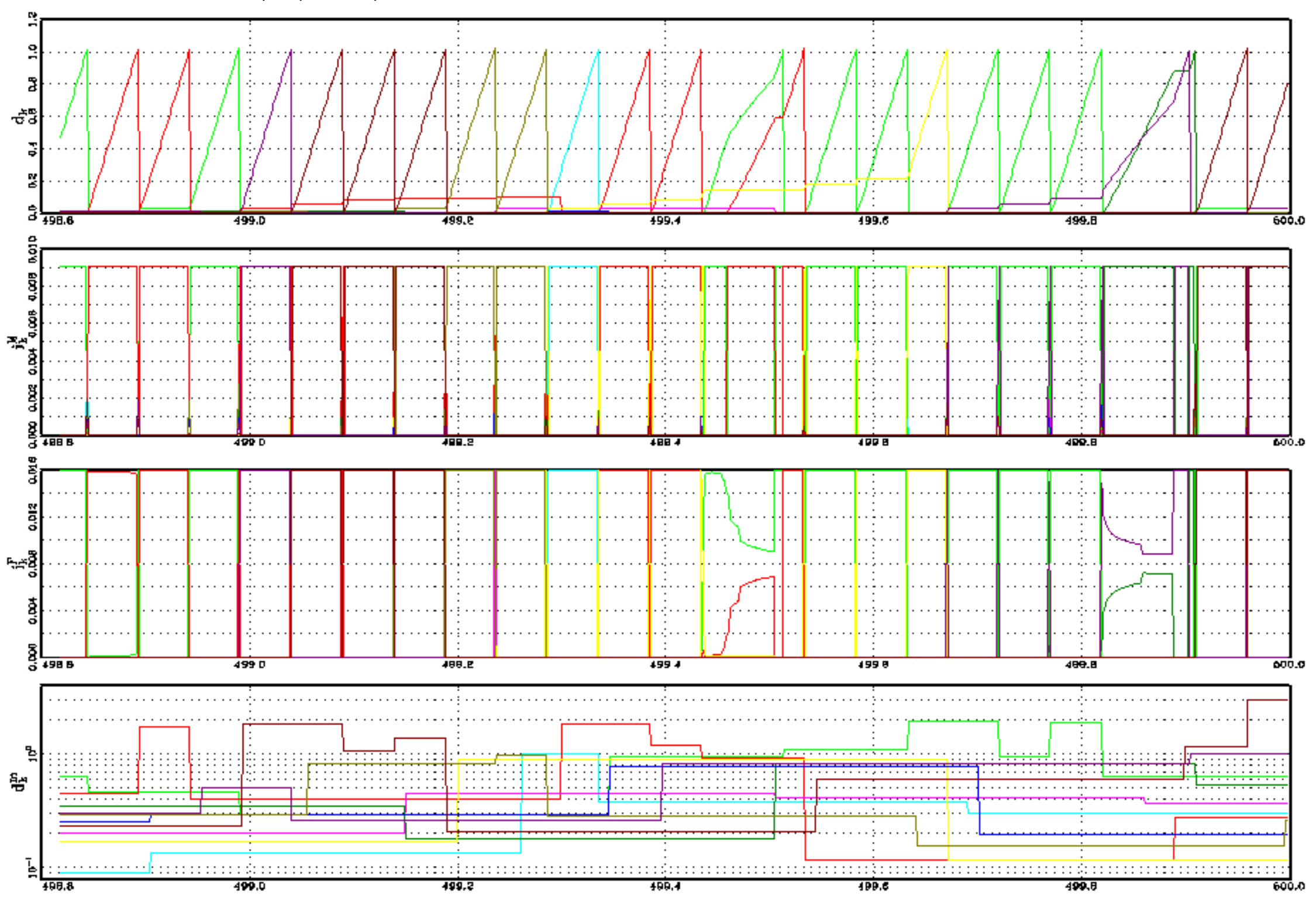
Figure 10: Evolution of $1+\theta_{r}$, fundamental and momentum investors. Simulation 6, run $\# 5$.

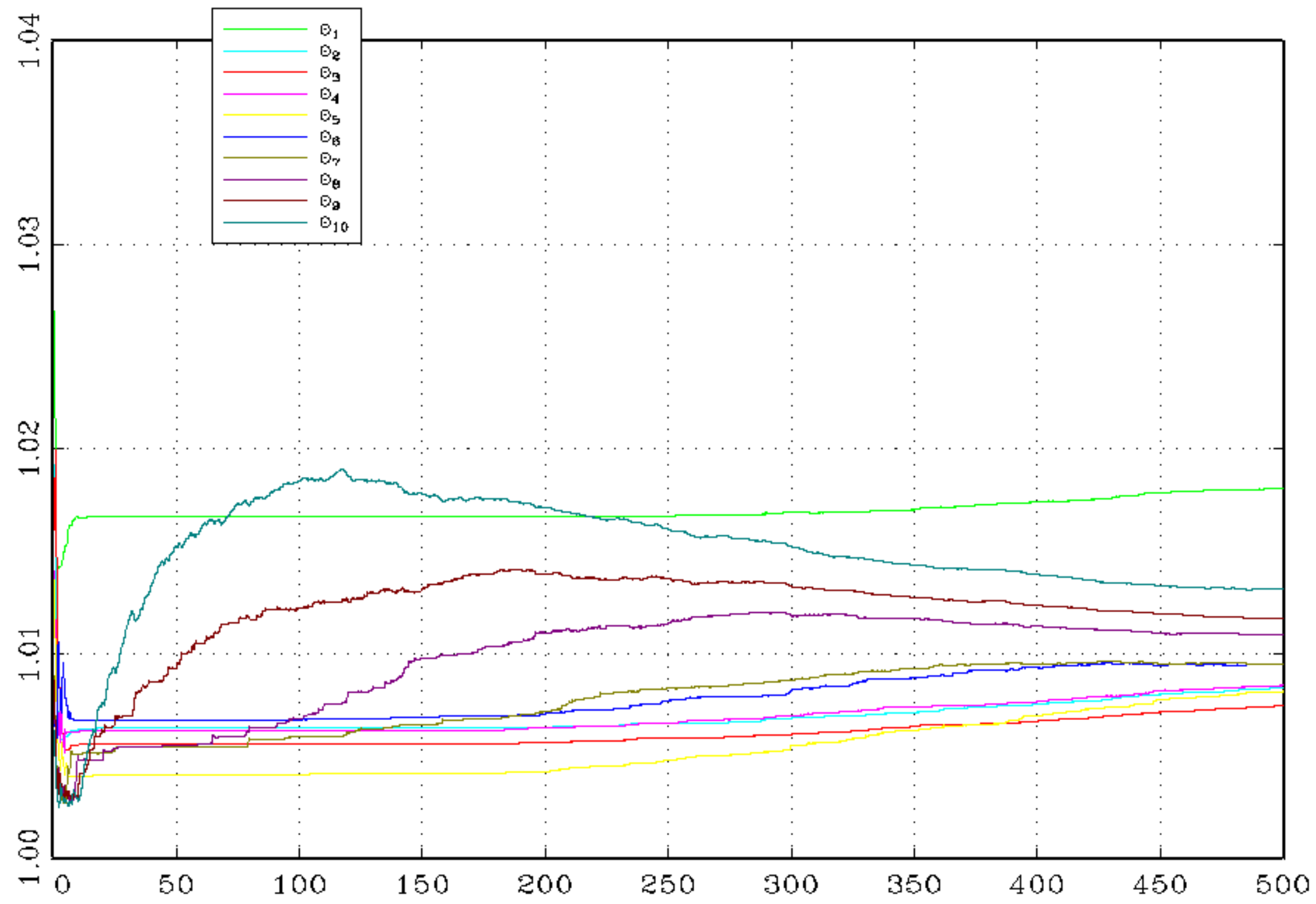

